Check for updates

Cite this: Phys. Chem. Chem. Phys., 2020, 22, 15751

Received 7th May 2020,

Accepted 24th June 2020

DOI: $10.1039 / \mathrm{d} 0 \mathrm{cp02479a}$

rsc.li/pccp

\title{
Electron spin relaxation properties of atomic hydrogen encapsulated in octavinyl POSS cages
}

\author{
George Mitrikas (D) * and Stavroula Menenakou
}

\begin{abstract}
The electron spin relaxation times of encapsulated atomic hydrogen in the vinyl derivative of silsesquioxane $\left(\mathrm{R}_{8} \mathrm{Si}_{8} \mathrm{O}_{12}\right)$ cages $\left(\mathrm{R}=\mathrm{CH}=\mathrm{CH}_{2}\right)$ are studied in detail by pulse electron paramagnetic resonance (EPR) methods in the temperature range between 10 and $300 \mathrm{~K}$. The temperature dependence of the spin-lattice relaxation time, $T_{1}$, shows similar behaviour with previously studied derivatives that typically involve Raman and thermally activated processes. The room-temperature phase-memory time $T_{M}=9 \mu$ s is comparable to those reported for different alkyl derivatives and exhibits a characteristic temperature dependence with a considerable reduction below $200 \mathrm{~K}$ as a result of dynamic effects like methyl group rotation. However, this reduction is modest for the vinyl derivative since the minimum observed $T_{M}=5 \mu$ s is much longer than the value of $1 \mu \mathrm{s}$ reported for methyl-containing derivatives like $\mathrm{R}=\mathrm{C}_{2} \mathrm{H}_{5}, \mathrm{C}_{3} \mathrm{H}_{7}$ (n-propyl), or OSi $\left(\mathrm{CH}_{3}\right)_{2} \mathrm{H}$. This discrepancy is attributed to the different rotation dynamics of the vinyl group, as evidenced by the determined activation energy and rotation frequency.
\end{abstract}

\section{Introduction}

After the discovery of the ability of polyhedral oligomeric silsesquioxane (POSS) cages to stably host atomic hydrogen upon $\gamma$-irradiation, ${ }^{1}$ many electron paramagnetic resonance (EPR) studies of the $\mathrm{H}^{\bullet}$ radical have been reported. ${ }^{2}$ Early works focused mainly on the electron $g$-value and the temperature dependence of the hyperfine coupling constant $A$ of the encapsulated hydrogen atom as a probe of its environment. ${ }^{3-5}$ Later determination of electron spin-lattice $\left(T_{1}\right)$ and phase memory $\left(T_{\mathrm{M}}\right)$ relaxation times using pulse EPR methods were often triggered by their potential application as qubit embodiments in a similar fashion to other molecular spin systems like for instance endohedral fullerenes $\left(\mathrm{N} @ \mathrm{C}_{60}\right.$ or $\left.\mathrm{P} @ \mathrm{C}_{60}\right){ }^{6}{ }^{6}$ While atomic hydrogen is more attractive due to its simpler electronic 1s state and the exceptionally large hyperfine coupling of about $1420 \mathrm{MHz}$, detailed pulse EPR studies of relevant parameters to quantum computing like $T_{1}$ and $T_{\mathrm{M}}$ are scarce and concern exclusively cages of the type $\mathrm{R}_{8} \mathrm{Si}_{8} \mathrm{O}_{12}$ with $\mathrm{R}=\mathrm{C}_{2} \mathrm{H}_{5},{ }^{7} \mathrm{R}=\mathrm{C}_{3} \mathrm{H}_{7}$ (n-propyl), ${ }^{8}$ and $\mathrm{R}=\mathrm{OSi}\left(\mathrm{CH}_{3}\right)_{2} \mathrm{H}^{9}{ }^{9}$ These studies showed that at ambient temperatures $T_{\mathrm{M}}$ ranges from 9 to $14 \mu \mathrm{s}$ and is determined by nuclear spin diffusion, whereas, below $200 \mathrm{~K}$ is abruptly reduced to $1 \mu \mathrm{s}$ and follows a temperature dependence characteristic of systems in which spins that are coupled to the paramagnetic center undergo a dynamic process that averages inequivalent environments. As the temperature is

Institute of Nanoscience and Nanotechnology, N.C.S.R. Demokritos, 15310 Athens, Greece. E-mail: g.mitrikas@inn.demokritos.gr; Fax: +30 210 6503323;

Tel: +30 2106503304 reduced, the latter process slows down and leads to a shortening of $T_{\mathrm{M}}$ due to the incomplete averaging of anisotropic hyperfine interactions. This is a very effective decoherence mechanism that is maximized when the rate of the dynamic process $R$ becomes equal to the splitting $\Delta$ that is averaged. ${ }^{10}$

Although slow processes like nuclear spin diffusion can be effectively suppressed by dynamical decoupling methods, ${ }^{11}$ this is not possible for mechanisms having short correlation times (typically $\tau_{\mathrm{c}}<100 \mathrm{~ns}$ ) like the rapid reorientation of methyl groups. ${ }^{12}$ As a consequence, all methyl-containing H@POSS derivatives would suffer from short $T_{\mathrm{M}}$ values in the lowtemperature range between 10 and $150 \mathrm{~K}$, despite the fact that the corresponding $T_{1}$ values are much longer ranging between $60 \mathrm{~s}$ and $1 \mathrm{~ms}$ in the same temperature interval. ${ }^{7-9}$ This peculiarity, which is intrinsic for all POSS cages possessing methyl groups in the organic substituents $\mathrm{R}$, could be a drawback for the implementation of H@POSS in quantum computing applications where long $T_{\mathbf{M}}$ values at low temperatures are required.

Herein we present a detailed electron spin relaxation study on the H@POSS derivative with $\mathrm{R}=\mathrm{CH}=\mathrm{CH}_{2},\left(\mathrm{CH}_{2} \mathrm{CH}\right)_{8} \mathrm{Si}_{8} \mathrm{O}_{12}$ (Fig. 1), containing an organic group with different rotational degrees of freedom compared to the previously reported $\mathrm{R}=$ $\mathrm{OSi}\left(\mathrm{CH}_{3}\right)_{2} \mathrm{H}$ (also termed $\left.\mathrm{Q}_{8} \mathrm{M}_{8}^{\mathrm{H}}\right) .{ }^{9}$ For the sake of completeness we additionally present the corresponding data for the species with $\mathrm{R}=\mathrm{OSi}\left(\mathrm{CH}_{3}\right)_{3}$, also known as $\mathrm{Q}_{8} \mathrm{M}_{8}$. The latter two species, namely $\mathrm{Q}_{8} \mathrm{M}_{8}^{\mathrm{H}}$ and $\mathrm{Q}_{8} \mathrm{M}_{8}$, have shown to exhibit the longest $T_{\mathrm{M}}$ value of $14 \mu \mathrm{s}$ at room temperature ${ }^{9}$ due to the larger electronegativity of $\mathrm{R}$ and the longer distance between the unpaired electron and the peripheral proton nuclei as compared to those 


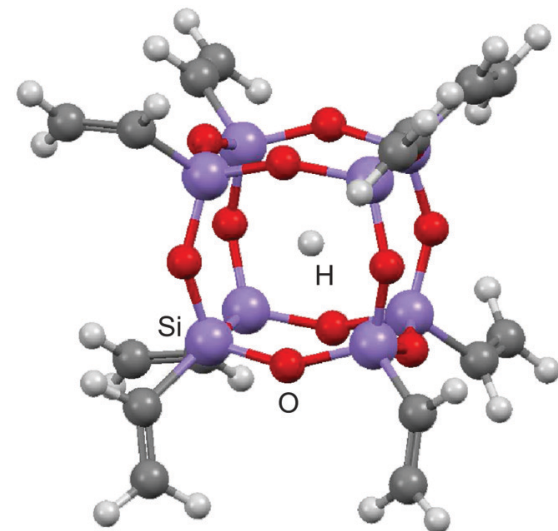

Fig. 1 Structure of $\mathrm{H}$ trapped in the cage cavity of octavinylsilsesquioxane $\left(\mathrm{H} @\left(\mathrm{CH}_{2} \mathrm{CH}\right)_{8} \mathrm{Si}_{8} \mathrm{O}_{12}\right)$.

of alkyl derivatives. ${ }^{2,8}$ While $\mathrm{H} @\left(\mathrm{CH}_{2} \mathrm{CH}\right)_{8} \mathrm{Si}_{8} \mathrm{O}_{12}$ does not differ considerably from $\mathrm{H} @ \mathrm{Me}_{8} \mathrm{Si}_{8} \mathrm{O}_{12}$ or $\mathrm{H} @ \mathrm{Et}_{8} \mathrm{Si}_{8} \mathrm{O}_{12}$ in terms of nuclear spin diffusion, and thus a $T_{\mathrm{M}}$ of $9 \mu$ s would be expected, one may anticipate a possible change on the temperature dependence of $T_{\mathrm{M}}$ for the vinyl derivative as a consequence of the reduced rotational modes of the organic substituent $\mathrm{R}$ dictated by the inhibited rotation about the carbon-carbon double bond. This aspect of relaxation dynamics has triggered our present work for two reasons: first, it is an excellent way to test our previous assignment of the low-temperature relaxation enhancement to methyl rotation, and second, it can give further insight into the relaxation mechanisms of H@POSS and thus help to design species with longer $T_{\mathrm{M}}$ values.

\section{Experimental}

\subsection{Sample preparation}

Octavinylsilsesquioxane $\left(\left(\mathrm{CH}_{2}=\mathrm{CH}\right)_{8} \mathrm{Si}_{8} \mathrm{O}_{12}\right.$, CAS 69655-76-1) was prepared by hydrolysis and subsequent condensation of trichlorovinylsilane $\left(\mathrm{CH}_{2}=\mathrm{CHSiCl}_{3}\right.$, CAS 75-94-5, 97\% Aldrich) that was used as received. ${ }^{13}$ In a $100 \mathrm{ml}$ round bottomed flask containing $72 \mathrm{ml}$ of ethanol cooled in an ice bath, $4 \mathrm{ml}$ of $\mathrm{CH}_{2}=\mathrm{CHSiCl}_{3}(31.2 \mathrm{mmol})$ were added dropwise with vigorous stirring. After that, a mixture of $8 \mathrm{ml}$ of ethanol and $4 \mathrm{ml}$ of water $(72 \mathrm{mmol})$ was added dropwise and the solution was stirred for a week at room temperature. The white fine crystalline precipitate was filtered off, further washed with methanol and finally dried in air at $70{ }^{\circ} \mathrm{C}$ to give $325 \mathrm{mg}$ of pure product (13\% yield). The compound was analysed by infrared spectroscopy revealing resonances at $3070 \mathrm{w}, 3028 \mathrm{w}, 2989 \mathrm{w}, 2960 \mathrm{w}$, $1605 \mathrm{~m}, 1410 \mathrm{~m}, 1275 \mathrm{~m}, 1165$ (sh), 1080s (br), 1000m, 965m, $775 \mathrm{~m}, 755 \mathrm{sh}), 566 \mathrm{~s}, 460 \mathrm{~m} \mathrm{~cm}^{-1}$. These are in excellent agreement with previously reported IR data of the same compound for which the structure was also analysed with X-ray crystallography. ${ }^{14}$

Encapsulation of atomic hydrogen was performed with $\gamma$-irradiation in steps using a ${ }^{60} \mathrm{Co}$ source. The accumulated dose was measured using Red Perspex Dosimeters, Type 4034 AD. $80 \mathrm{mg}$ of POSS powder were mixed with $16 \mathrm{mg}$ of $\mathrm{I}_{2}(\mathrm{~s})$ (acting as radical scavenger), placed in a sealed vial and irradiated for 24 days resulting in a total dose of $240 \mathrm{kGy}$. After $\gamma$-irradiation the powder was purified by the precipitation method using methanol to remove iodine. The recovered powder was dried under vacuum $\left(10^{-1}\right.$ mbar) for $1 \mathrm{~h}$ and $25 \mathrm{mg}$ of the sample was transferred into an EPR quartz tube. Comparison of the cw EPR spectrum (in the presence of $\mathrm{O}_{2}$, unsaturated conditions) with a standard sample gave an estimate of $7.5 \times 10^{15}$ spins per $\mathrm{cm}^{3}$ for the electron spin concentration. To avoid paramagnetic oxygen in pulsed EPR measurements, the quartz tube was filled with He gas following the procedure described previously. ${ }^{9}$

\subsection{Spectroscopy}

Infrared spectra were recorded at room temperature on asprepared powders using the Attenuated Total Reflection (ATR) technique with a PerkinElmer Spectrum 100 FTIR spectrometer (range $400-4000 \mathrm{~cm}^{-1}$ ).

EPR measurements at the X-band were carried out on a Bruker ESP 380E spectrometer equipped with a rectangular ER 4102ST cavity (continuous wave (cw) mode) or an EN 4118XMD4 Bruker resonator (pulse mode). Low temperature measurements were performed with a helium cryostat from Oxford Inc. (at temperatures between 10 and $300 \mathrm{~K}$ ). The microwave frequency was measured with a HP 5350B microwave frequency counter. The temperature was stabilized with an Oxford ITC4 temperature controller within $\pm 0.1 \mathrm{~K}$. The magnetic field was calibrated using a DPPH standard. The relaxation measurements were performed at the low-field EPR transition. The repetition rate was properly adjusted in every measurement in order to avoid saturation.

The electron spin-lattice relaxation times $T_{1}$ were measured by inversion recovery with the pulse sequence $\pi-t-\pi / 2-\tau-\pi-\tau-$ echo. The lengths of the mw $\pi / 2$ and $\pi$ pulses were 16 and $32 \mathrm{~ns}$, respectively, and the interpulse delay $\tau=600 \mathrm{~ns}$. For each trace, 100 data points were collected with an appropriate time increment to ensure complete magnetization recovery. The phase-memory times $T_{\mathrm{M}}$ were measured by the two-pulse echo decay sequence, $\pi / 2-t-\pi-t$-echo, with $t$ varying.

At temperatures lower than $20 \mathrm{~K}$, where $T_{1}$ exceeds the maximum instrumental shot repetition time of $2 \mathrm{~s}$, the electron spin echo was recorded with a HP Infinium 54810A oscilloscope which allowed the acquisition of the entire time trace in a single shot. The corresponding $T_{1}$ values were obtained with the saturation method: after saturation using a fast repetition rate, the microwave irradiation was interrupted and the system allowed to relax for time $t$ which was recorded with a chronometer. The recovered magnetization was measured with a two-pulse echo in a single-shot experiment recorded with the oscilloscope.

\subsection{Data manipulation}

The data were processed with the program MATLAB 7.0 (The MathWorks, Natick, MA). $T_{1}$ relaxation times were determined by fitting the time traces with single exponential functions. For obtaining $T_{\mathrm{M}}$ a stretched exponential function was used. $\mathrm{cw}-$ EPR spectra were simulated with the EasySpin package. ${ }^{15}$ For 
powder spectra simulations the isotropic spin Hamiltonian $\mathscr{H}=g \beta_{\mathrm{e}} B / h S_{z}-g_{\mathrm{H}} \beta_{\mathrm{n}} B / h I_{z}+A_{\text {iso }} S_{z} I_{z}$ was used, where $g$ and $g_{\mathrm{H}}$ are the electron and nuclear $g$-factors, $\beta_{\mathrm{e}}$ and $\beta_{\mathrm{n}}$ are the Bohr and nuclear magnetons, $A_{\text {iso }}$ is the proton hyperfine coupling constant, and $B$ is the static magnetic field along $z$-axis. For fluid solution spectra, the superhyperfine term $\sum_{i=1}^{N}\left(-g_{\mathrm{Si}} \beta_{\mathrm{n}} B / h I_{z}^{i}+A^{29} \mathrm{Si}_{z} S_{z} I_{z}^{i}\right)$ was added with $N=1$ and $N=2$ for the species with one and two ${ }^{29} \mathrm{Si}$ atoms in the POSS core cage, respectively.

\section{Results and discussion}

\section{1 cw-EPR spectroscopy}

The room-temperature EPR spectrum of $\mathrm{H} @\left(\mathrm{CH}_{2} \mathrm{CH}\right)_{8} \mathrm{Si}_{8} \mathrm{O}_{12}$ is shown in Fig. 2(a). Apart from the two characteristic EPR transitions of $\mathrm{H}^{\bullet}$ that are separated by about $50.8 \mathrm{mT}$, there is also a weak signal around $g=2$ that is attributed to radiationinduced free radicals. This signal, which is stronger if $\mathrm{O}_{2}$ is used as radical scavenger instead of $\mathrm{I}_{2}(\mathrm{~s})$, decays to noise level within a couple of days when the sample is exposed to air.

Fig. 2(b) shows a closer inspection of the inhomogeneously broadened resonance lines having $\Delta B_{\mathrm{pp}}=0.14 \mathrm{mT}$. The simultaneous simulation of both spectra gave $g=2.00282(10), A_{\text {iso }}=$ 1414.2(2) $\mathrm{MHz}$, and a Gaussian lineshape with a FWHM of $4.90(5) \mathrm{MHz}$, which are close to the values reported previously for alkyl-substituted derivatives. ${ }^{8}$

The ${ }^{29} \mathrm{Si}$ isotropic hyperfine coupling, $A_{29} \mathrm{Si}$, can be obtained from the analysis of the solution EPR spectra shown in Fig. 2(c). The spectra have narrow linewidths $\Delta B_{\mathrm{pp}}=10.8 \mu \mathrm{T}$ and exhibit satellite peaks separated by $0.149 \mathrm{mT}$ that are assigned to the hyperfine interaction between the unpaired electron and ${ }^{29} \mathrm{Si}$ atoms of the POSS cage. Assuming all eight positions are magnetically equivalent and taking into account the natural abundance $4.67 \%$ of ${ }^{29} \mathrm{Si}$, the abundance of POSS species with none (singlet), one (doublet), and two (triplet) ${ }^{29} \mathrm{Si}$ atoms is calculated by the binomial distribution as $68.15 \%, 26.79 \%$ and $4.58 \%$, respectively. These three species constitute more then $99.5 \%$ of the total paramagnetic centres and thus their properly weighted signals reproduce accurately the relative intensities of peaks in the experimental EPR spectrum as can be seen in Fig. 2(c). A nearly Gaussian lineshape with a FWHM of $11.2 \mu \mathrm{T}$ was used for the simulation which included convolution with a $4 \mu \mathrm{T}$ Lorentzian peak for better fit. The obtained isotropic simulation parameters $g=2.00276(5), A_{\text {iso }}=1414.3(1) \mathrm{MHz}$ and $\left|A_{29} \mathrm{Si}\right|=4.20(2) \mathrm{MHz}$ are in very good agreement with the values found for alkyl-POSS, especially with those of $\mathrm{H} @ \mathrm{Et}_{8} \mathrm{Si}_{8} \mathrm{O}_{12}{ }^{2,8}$

\subsection{Spin-lattice relaxation}

The obtained room-temperature spin-lattice relaxation time $T_{1}=42 \mu \mathrm{s}$ is similar to that reported for $\mathrm{Q}_{8} \mathrm{M}_{8}^{\mathrm{H}}$ (ref. 9) and to that measured for $\mathrm{Q}_{8} \mathrm{M}_{8}$ in the present study. The single exponential character of $T_{1}$-decay is retained over the whole temperature range as can be seen in Fig. 3. Interestingly, the value of $62.5 \mathrm{~s}$ measured at $10 \mathrm{~K}$ is - to the best of our
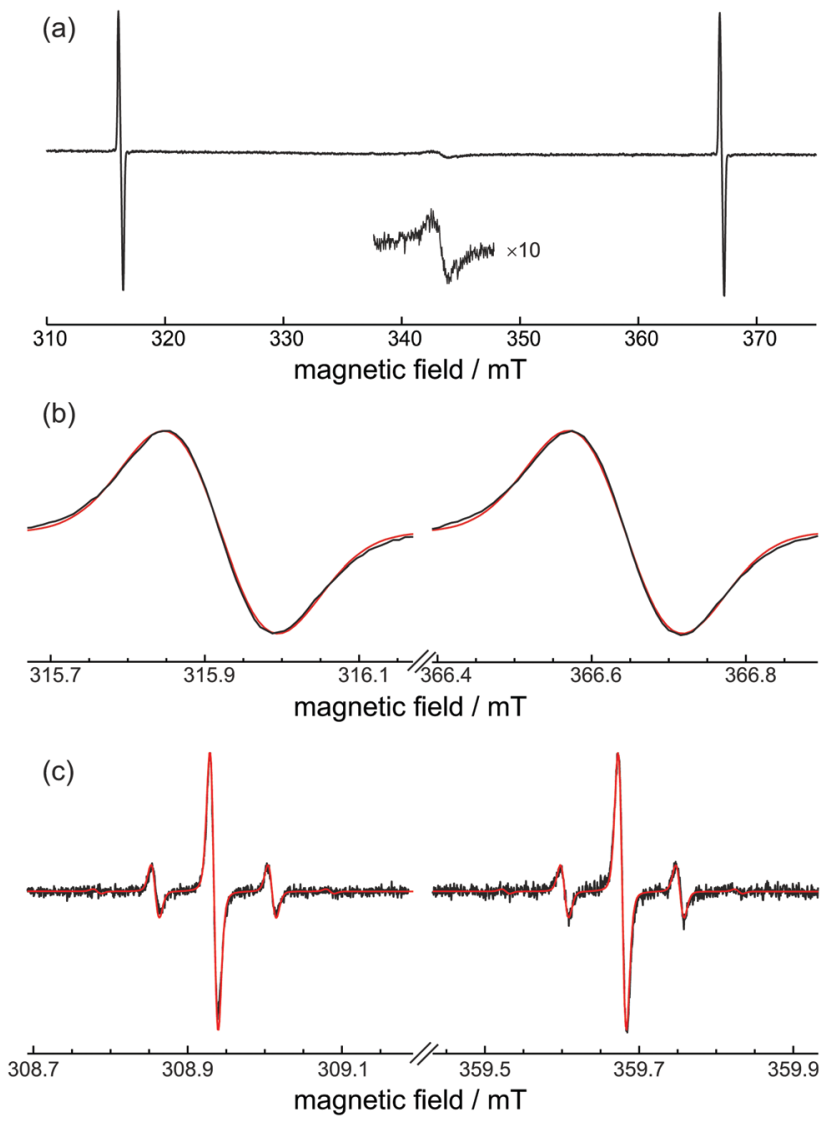

Fig. 2 Room-temperature cw-EPR spectra of $\mathrm{Ha}\left(\mathrm{CH}_{2} \mathrm{CH}\right)_{8} \mathrm{Si}_{8} \mathrm{O}_{12}$. (a) Powder spectrum. Experimental conditions: mw frequency, $9.619 \mathrm{GHz}$; mw attenuation, $40 \mathrm{~dB}$; modulation amplitude, $100 \mu \mathrm{T}$; modulation frequency, $100 \mathrm{kHz}$. (b) Details of the two resonance lines (black traces) together with the simulation (red traces). (c) Fluid solution spectrum in degassed THF (black traces) and the simulation (red traces) assuming isotropic $\mathrm{H}$ and ${ }^{29} \mathrm{Si}$ hyperfine couplings and taking into account the natural abundance $4.67 \%$ of ${ }^{29} \mathrm{Si}$. Experimental conditions: $\mathrm{mw}$ frequency, $9.424 \mathrm{GHz}$; mw attenuation, $30 \mathrm{~dB}$; modulation amplitude, $5 \mu \mathrm{T}$; modulation frequency, $100 \mathrm{kHz}$. For simulation parameters see text.

knowledge - the longest reported $T_{1}$ value for trapped hydrogen atoms.

The temperature dependence of the spin-lattice relaxation rate $1 / T_{1}$ is displayed in Fig. 4. From the "Raman" $1 / T_{1}$ vs. $T$ log-log representation shown in Fig. 4(a) it is evident that more than one relaxation processes exist. At both low and high temperatures the relaxation rate obeys a $T^{3}$ dependence, whereas, for intermediate temperatures $70 \mathrm{~K}<T<150 \mathrm{~K}$ a stronger $T^{5}$ dependence is observed. This result suggests that apart from the usual twophonon Raman process (scaling as $T^{2}$ at the high-temperature limit), there is at least one additional process that is characterized by a stronger than $T^{2}$ dependence at high temperatures, namely Orbach, local-mode, or thermally activated process. ${ }^{16}$

Following the arguments of our previous work on $\mathrm{Q}_{8} \mathrm{M}_{8}^{\mathrm{H}},{ }^{9}$ we modelled the present data with a sum of Raman and thermally activated processes given by

$$
\frac{1}{T_{1}}=A_{\text {Ram }}\left(\frac{T}{\theta_{\mathrm{D}}}\right)^{7} J_{6}\left(\frac{\theta_{\mathrm{D}}}{T}\right)+A_{\text {therm }}\left[\frac{2 \tau_{\mathrm{c}}}{1+\omega^{2} \tau_{\mathrm{c}}^{2}}\right]
$$



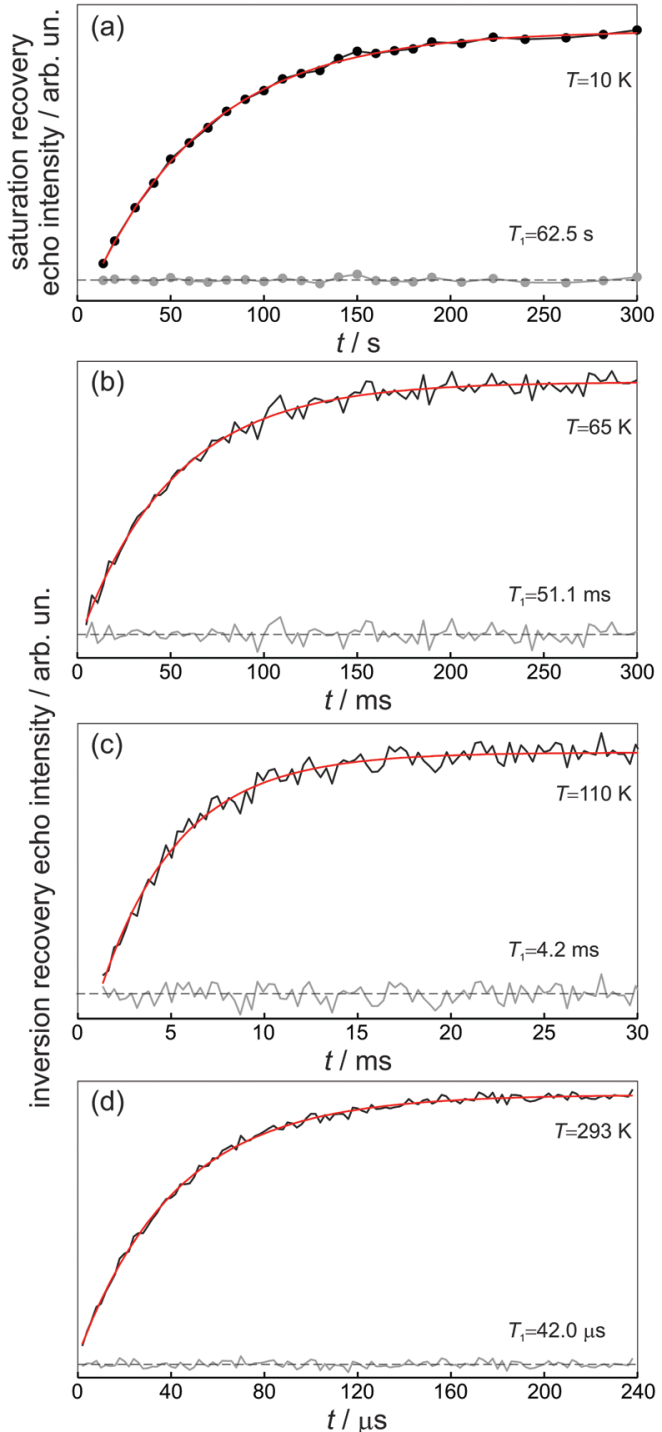

Fig. 3 Saturation (a) and inversion (b-d) recovery data at four different temperatures and superimposed exponential fits. The differences between experimental and fitted curves are shown at the bottom (gray traces).

where $T$ is the temperature in Kelvin, $A_{\text {Ram }}$ is the coefficient for the Raman process, $\theta_{\mathrm{D}}$ is the Debye temperature, $J_{6}$ is the transport integral,

$$
J_{6}\left(\frac{\theta_{\mathrm{D}}}{T}\right)=\int_{0}^{\theta_{\mathrm{D}} / T} \frac{x^{6} \mathrm{e}^{x}}{\left(\mathrm{e}^{x}-1\right)^{2}} \mathrm{~d} x,
$$

$A_{\text {therm }}$ is the coefficient for the contribution from a thermally activated process, $\tau_{\mathrm{c}}$ is the correlation time and is equal to $\tau_{\mathrm{c}}=$ $\tau_{\mathrm{c} 0} \exp \left(E_{\mathrm{a}} / k_{\mathrm{B}} T\right), E_{\mathrm{a}}$ is the activation energy, $\tau_{\mathrm{c} 0}$ is the preexponential factor, and $\omega$ is the EPR frequency. The fitting curve with the parameters shown in Fig. 4 is in good agreement with experimental points.

On the other hand, from the Orbach $1 / T_{1}$ vs. $1 / T$ semi-log representation shown in Fig. 4(b), one could also assume the presence of two Orbach processes $\left(1 / T_{1} \propto \Delta^{3} /\left(\mathrm{e}^{4 / T}-1\right)\right)$ with $73 \mathrm{~K}(6.3 \mathrm{meV})$ and $\Delta_{2}=811 \mathrm{~K}(69.9 \mathrm{meV})$ at the low and high
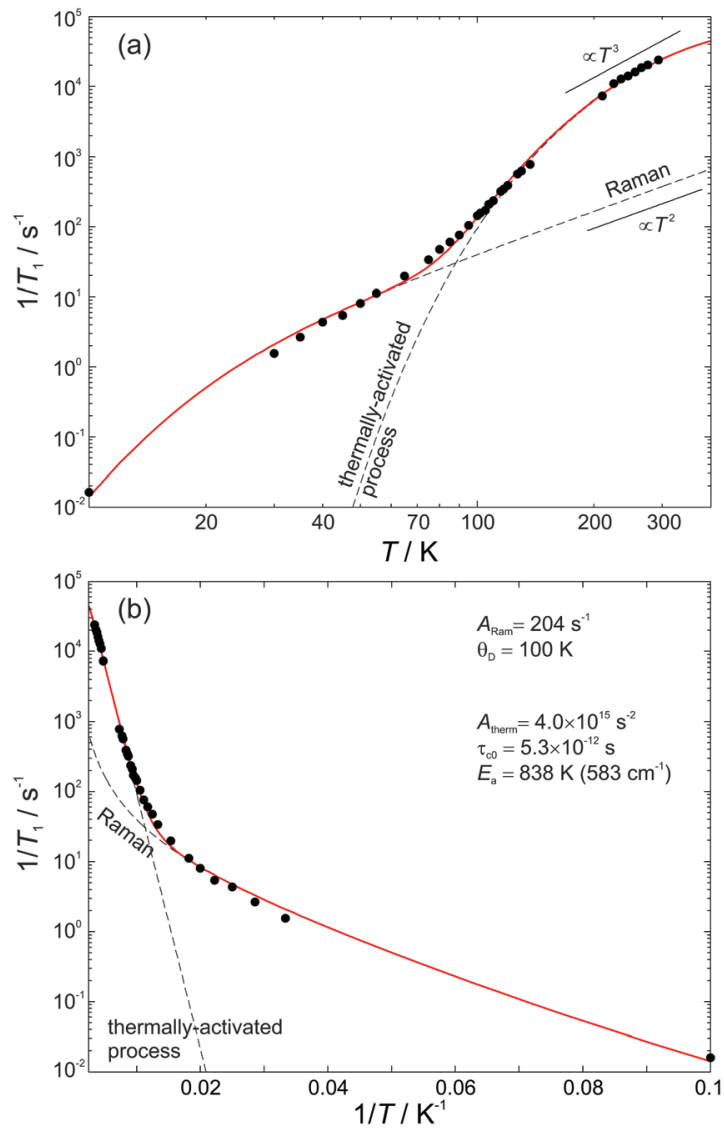

Fig. 4 Temperature dependence of the spin-lattice relaxation rate and the fitting curve using eqn (1). The dashed lines are the Raman and thermally activated contributions to the total relaxation rate. (a) "Raman" and (b) "Orbach" representation with the fitting parameters.

temperature limits, respectively. However, given that such lowlying excited electronic states do not exist in atomic hydrogen, we may conclude that the Orbach process is rather unlikely and that the low temperature data can be best described by a Raman process with $\theta_{\mathrm{D}}=100 \mathrm{~K}$.

For the high temperature data, a clear decision between a thermally activated and a local process cannot be made because these two processes exhibit similar $1 / T_{1}$ temperature dependence for $T<E_{\text {a }}$ (or $T<\Delta_{\text {loc}}$ ). Measurements at higher microwave frequencies could help to distinguish between the two because for the thermally activated process the relaxation rate decreases at sufficiently high EPR frequency, $\omega$. However, a previous study on $\mathrm{H} @ \mathrm{Et}_{8} \mathrm{Si}_{8} \mathrm{O}_{12}{ }^{7}$ showed that $1 / T_{1}$ was slightly increased when measurements were performed at high-field EPR, a situation compatible with the field dependence of the Raman process. ${ }^{17}$ This result indicates that the disentanglement of $T_{1}$ processes may be more complex. Nevertheless, on the basis of our previous analysis ${ }^{9}$ we model the high-temperature spin-lattice relaxation data as a thermally-activated rather than a local mode process. This is because a local mode process will have a finite probability if the local-mode energy $\Delta_{\text {loc }}$ is less than twice the Debye temperature. ${ }^{18}$ Considering an experimentally determined $\Delta_{\text {loc }}=811 \mathrm{~K}$, which is related to the high-temperature activation 
energy, it is obvious that a local mode process is inconsistent with the previous Raman analysis and $\theta_{\mathrm{D}}=100 \mathrm{~K}$. Interestingly, the obtained activation energy $E_{\mathrm{a}}=583 \mathrm{~cm}^{-1}$ is close to the strong infrared absorption observed at $566 \mathrm{~cm}^{-1}$ that is assigned to deformation vibrations $d(\mathrm{O}-\mathrm{Si}-\mathrm{O})$ and $\delta(\mathrm{Si}-\mathrm{C}=\mathrm{C}) .{ }^{14}$

It should be noted that, contrary to previous results, where $T_{1}$ was found to depend strongly on the side groups $\mathrm{R}$ and to expand with their size ${ }^{8}$ the similarity of the room-temperature $T_{1}$ value of $42 \mu \mathrm{s}$ observed for the three POSS derivatives in our present study indicates a modest dependence of $T_{1}$ on the type of the organic substituent R. This implies that the spin-lattice relaxation is mainly determined by the dynamics of the core cage, $\mathrm{Si}_{8} \mathrm{O}_{12}$. On the other hand, as will be shown in the following section, $T_{\mathrm{M}}$ depends strongly on the choice of side groups R and this property could be the key for controlling the electron spin coherence of H@POSS.

\subsection{Spin-spin relaxation}

The transverse electron spin relaxation time, $T_{2}$, is probed through the two-pulse sequence shown in Fig. 5. Decay traces measured at different temperatures show typical stretchedexponential behaviour that can be fitted with

$$
I(2 \tau)=I_{0} \exp \left[-\left(\frac{2 \tau}{T_{\mathrm{M}}}\right)^{n}\right],
$$

where $\tau$ is the interpulse delay, $n$ is a parameter determined by the mechanism of phase memory decay and the rate, $W$, of the dephasing process relative to $\tau$, and $T_{\mathrm{M}}$ is the so-called phase memory time encompassing $T_{2}$ and all other processes that cause electron spin dephasing. ${ }^{17}$ The experimentally determined range of parameter $n, 1.5 \leq n \leq 2$, implies a slow dynamic process with $W \tau \ll 1$. For systems of low paramagnetic concentration and proton-containing ligands like the ones presented here, a very effective dephasing mechanism is the so-called nuclear spin diffusion. ${ }^{19}$ According to this, two neighbouring proton nuclear spins can undergo mutual spin flips with typical rates of $W \sim 10 \mathrm{kHz}$, which in turn modulate the electron-nuclear dipolar interaction.

The room-temperature phase memory time of $\mathrm{H} @\left(\mathrm{CH}_{2} \mathrm{CH}\right)_{8}$ $\mathrm{Si}_{8} \mathrm{O}_{12}, T_{\mathrm{M}}=9.1 \mu \mathrm{s}$, is similar to that observed previously for alkyl derivatives ${ }^{8}$ but smaller than $T_{\mathrm{M}}=14 \mu$ s found for $\mathrm{H} @ \mathrm{Q}_{8} \mathrm{M}_{8}^{\mathrm{H}}$ (ref. 9) and $\mathrm{H} @ \mathrm{Q}_{8} \mathrm{M}_{8} \cdot{ }^{11}$ This result provides strong evidence that different characteristics of $\mathrm{R}$ like electronegativity, number of hydrogen atoms and their proximity to the trapped hydrogen are key factors that determine $T_{\mathrm{M}}$ at ambient temperature. Species with larger $\mathrm{R}$ group electronegativity, $\chi_{\text {Group }}$, exhibit smaller spin delocalization and, therefore, weaker interactions with the cage magnetic nuclei, as is evidenced by the larger $A_{\text {iso }}$ and the smaller $\left|A_{29}{ }_{\mathrm{Si}}\right|$ hyperfine coupling constants. ${ }^{2}$ Moreover, POSS derivatives bearing more distant protons in $\mathrm{R}$ may have different nuclear spin diffusion since the hyperfine interaction for such protons is purely dipolar and the diffusion barrier radius is strongly affected by the anisotropy of the local dipolar field. ${ }^{17}$ On the other hand, the temperature dependence of $T_{\mathrm{M}}$ reveals that the dynamics of cage substituents is a crucial parameter too. For instance, Fig. 6(a) shows that for

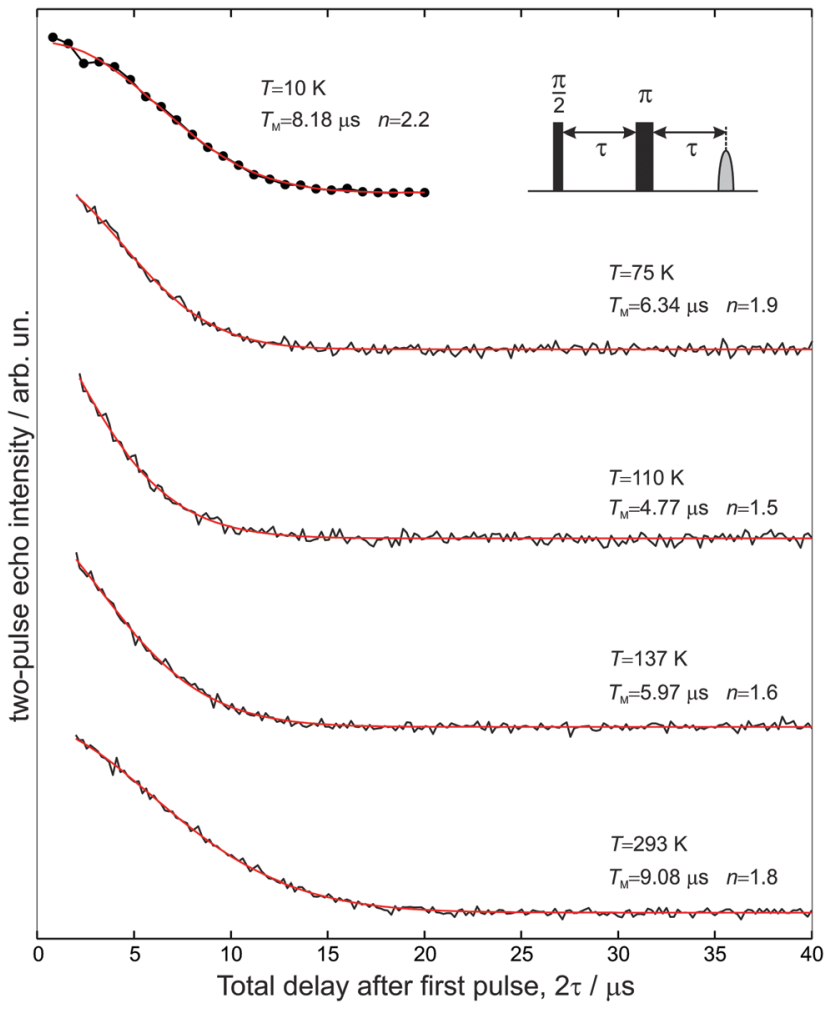

Fig. 5 Two-pulse electron spin echo decays measured at five different temperatures as a function of $2 \tau$, and the superimposed stretched exponential fits using eqn (3).

the two species $\mathrm{H} @ \mathrm{Q}_{8} \mathrm{M}_{8}^{\mathrm{H}}$ and $\mathrm{H} @ \mathrm{Q}_{8} \mathrm{M}_{8} T_{\mathrm{M}}$ exhibits quite different temperature dependence within the range $50 \mathrm{~K}<$ $T<200 \mathrm{~K}$, whereas, for $T>200 \mathrm{~K}$ they are identical. This result supports our previous assignment of the low-temperature relaxation enhancement to the rotation of methyl groups and clearly shows that small changes in the rotation dynamics of $\mathrm{R}\left(\mathrm{OSi}\left(\mathrm{CH}_{3}\right)_{2} \mathrm{H}\right.$ vs. OSi $\left.\left(\mathrm{CH}_{3}\right)_{3}\right)$ can have important impact on the electron spin relaxation properties.

The case of $\mathrm{H} @\left(\mathrm{CH}_{2} \mathrm{CH}\right)_{8} \mathrm{Si}_{8} \mathrm{O}_{12}$ shows clear differences compared to $\mathrm{H} @ \mathrm{Q}_{8} \mathrm{M}_{8}^{\mathrm{H}}$ and $\mathrm{H} @ \mathrm{Q}_{8} \mathrm{M}_{8}$. First, the temperature range of $T_{\mathbf{M}}$ shortening is narrower and, second, the percentage reduction of the room-temperature $T_{\mathrm{M}}$ value is smaller. Moreover, the minimum value of $T_{\mathrm{M}}=5 \mu \mathrm{s}$ observed at $T=110 \mathrm{~K}$ is about five times longer than the corresponding value of $\mathrm{H} @ \mathrm{Q}_{8} \mathrm{M}_{8}$.

The temperature dependence of $T_{M}$ shown in Fig. 6(a) can be analyzed in terms of the rotation of methyl groups acting as a dynamic process that averages inequivalent environments. The physical motion of a methyl proton between two sites that have different resonance frequencies $\omega_{1}$ and $\omega_{2}$ due to the different hyperfine interactions with the unpaired electron, can modulate the EPR frequency of the paramagnetic centre and thus contribute to electron spin dephasing. The effect is similar to the classic two site exchange phenomenon and has been treated theoretically for the case of secular hyperfine interactions. ${ }^{20}$ Assuming a correlation time $\tau_{\mathrm{c}}=\tau_{\mathrm{c} 0} \exp \left(E_{\mathrm{a}} / k_{\mathrm{B}} T\right)$ for the jumping motion between the two sites, with $E_{\mathrm{a}}$ being the 
(a)

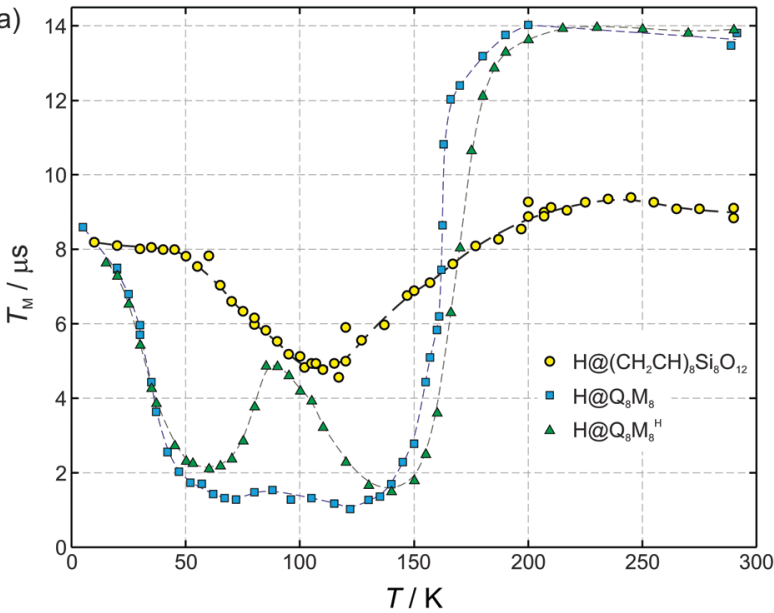

(b)

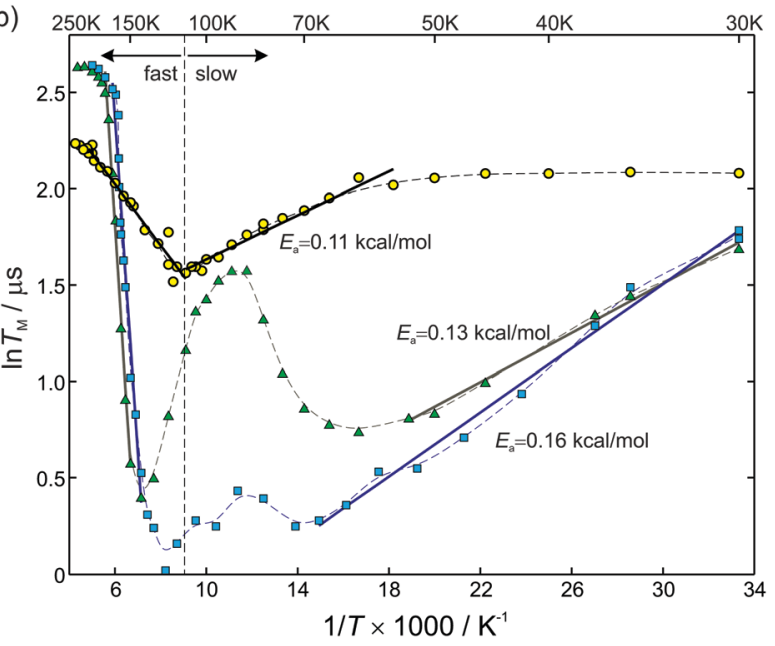

Fig. 6 (a) Temperature dependence of phase memory times $T_{M}$ for three different POSS derivatives: $\left(\mathrm{CH}_{2} \mathrm{CH}\right)_{8} \mathrm{Si}_{8} \mathrm{O}_{12}$ (circles), $\mathrm{Q}_{8} \mathrm{M}_{8}$ (squares), and $\mathrm{Q}_{8} \mathrm{M}_{8}^{\mathrm{H}}$ (triangles, modified with permission from ref. 9, copyright (C) the Owner Societies 2012). Dashed curves connect data points. (b) Data in the $\ln T_{M}$ vs. $1 / T$ representation. Straight lines are fits with Arrhenius equation for the case of slow $(T<110 \mathrm{~K})$ and fast $(T>110 \mathrm{~K})$ motional limit, respectively. The fitting parameters for the fast motional limit are $E_{\mathrm{a}}=0.31 \mathrm{kcal} \mathrm{mol}^{-1}$ for $\left(\mathrm{CH}_{2} \mathrm{CH}\right)_{8} \mathrm{Si}_{8} \mathrm{O}_{12}, E_{\mathrm{a}}=3.4 \mathrm{kcal} \mathrm{mol}^{-1}$ for $\mathrm{Q}_{8} \mathrm{M}_{8}$, and $E_{a}=3.6 \mathrm{kcal} \mathrm{mol}^{-1}$ for $\mathrm{Q}_{8} \mathrm{M}_{8}^{\mathrm{H}}$.

activation energy and $\tau_{\mathrm{co}}$ the preexponential factor, we define the rate of process $R=1 / \tau_{\mathrm{c}}$ and the energy difference $\Delta=\delta \omega /$ $2=\left(\omega_{1}-\omega_{2}\right) / 2$. In the fast motional limit, $R \gg \Delta$, the echo decay is given by ${ }^{10}$

$$
I(2 \tau)=I_{0} \exp \left[-2 \tau\left(\frac{\Delta^{2} \tau_{\mathrm{c}}}{2}\right)\right],
$$

with the relaxation time

$$
T_{\mathrm{M}}=\frac{2}{\Delta^{2} \tau_{\mathrm{c}}}
$$

In this fast motional limit the relaxation time $T_{\mathrm{M}}$ is reduced as the temperature is decreased. From the slope of the Arrhenius plot shown in Fig. 6(b) we can deduce the rotation barrier $E_{\mathrm{a}} / k_{\mathrm{B}}=158 \pm 7 \mathrm{~K}$ or $E_{\mathrm{a}}=0.31 \pm 0.01 \mathrm{kcal} \mathrm{mol}^{-1}$ for $\mathrm{H} @\left(\mathrm{CH}_{2} \mathrm{CH}\right)_{8} \mathrm{Si}_{8} \mathrm{O}_{12}$. Interestingly, this is about an order of magnitude smaller than the value $E_{\mathrm{a}}=3.4 \mathrm{kcal} \mathrm{mol}^{-1}$ obtained

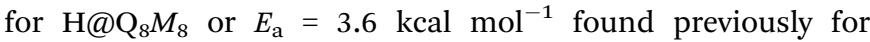
$\mathrm{H} @ \mathrm{Q}_{8} \mathbf{M}_{8}^{\mathrm{H}} \cdot{ }^{9}$ The latter two values are typical for activation energies of methyl group rotation as probed by nuclear magnetic resonance $(\mathrm{NMR})^{21,22}$ or neutron scattering methods. ${ }^{12}$ The much lower value found here for $\mathrm{H} @\left(\mathrm{CH}_{2} \mathrm{CH}\right)_{8} \mathrm{Si}_{8} \mathrm{O}_{12}$ implies a virtually free rotation as compared to the other two species. Given the fact that rotation about the carbon-carbon double bond is not allowed, one can assume that the rotation barrier $E_{\mathrm{a}}=0.31 \mathrm{kcal} \mathrm{mol}^{-1}$ corresponds to reorientation of the vinyl groups around the $\mathrm{Si}-\mathrm{C}$ bonds. We note here that such a free rotation is a peculiar result since any $\mathrm{sp}^{2}$ character of the vinyl $\mathrm{Si}-\mathrm{C}$ bond should hinder rotation. On the other hand, a previous NMR study of $\left(\mathrm{CH}_{2} \mathrm{CH}\right)_{8} \mathrm{Si}_{8} \mathrm{O}_{12}$ revealed the rapid anisotropic reorientation of the vinyl groups around the $\mathrm{Si}-\mathrm{C}$ bonds with a frequency higher than $100 \mathrm{kHz} .{ }^{14}$ Although no activation energy was reported for this dynamic process, the magnitude of rotation frequency is in line with our $T_{\mathrm{M}}$ results. Assuming $R=1 / \tau_{\mathrm{c}}=100 \mathrm{kHz}$ and taking $\Delta=200 \mathrm{kHz}$ (vide infra), eqn (5) gives $T_{\mathrm{M}}=5 \mu \mathrm{s}$ which is in expellant agreement with the corresponding experimental value at $T=110 \mathrm{~K}$. On the basis of this agreement and the lack of experimental $E_{\mathrm{a}}$ values from other methods, we assign the obtained $E_{\mathrm{a}}=0.31 \mathrm{kcal} \mathrm{mol}^{-1}$ to reorientation of the vinyl groups around the $\mathrm{Si}-\mathrm{C}$ bonds. The unexpected low value could be linked to steric hindrance effects also related to the solid-state phase of the samples.

In the slow motional limit, $R \ll \Delta$, the two-pulse echo decays with the relaxation time $T_{\mathrm{M}}=\tau_{\mathrm{c}}$ which increases as the temperature is decreased. The corresponding data for $\mathrm{H} @\left(\mathrm{CH}_{2} \mathrm{CH}\right)_{8} \mathrm{Si}_{8} \mathrm{O}_{12}$ in the range $55 \mathrm{~K}<T<110 \mathrm{~K}$ also follow a linear relation in the $\ln T_{\mathrm{M}} v s .1 / T$ representation shown in Fig. 6(b). However, the obtained rotation barrier $E_{\mathrm{a}} / k_{\mathrm{B}}=57 \pm 3 \mathrm{~K}$ or $E_{\mathrm{a}}=0.11 \pm$ $0.01 \mathrm{kcal} \mathrm{mol}^{-1}$ is considerably smaller than the corresponding one found for the fast motional limit. On the other hand, similar values for $E_{\mathrm{a}}$ were found for the other two species, indicating that the low activation energy is a common attribute of all systems in the slow motional limit despite the composition of R. The origin of this peculiarity could be the contribution of nonsecular and pseudosecular hyperfine interactions to the dephasing mechanism. Kispert et al. ${ }^{10}$ recognized that the motion of a $\mathrm{CH}_{2}$ group produces an additional effect if the effective fields at the two proton positions are not parallel; the nuclear spin will sometimes change due to the motion, in a similar manner that anisotropic hyperfine interaction mixes EPR and NMR states and gives rise to - otherwise - forbidden NMR transitions. ${ }^{23}$ Although this effect is smeared out in the fast motional limit, it can cause $T_{\mathrm{M}}$ to deviate from $\tau_{\mathrm{c}}$ in the slow motional limit as has been observed for radicals in crystals. ${ }^{10}$

The small activation energies obtained from data measured at low temperatures may also be linked to tunneling effects of methyl groups. As a consequence of tunneling, the temperature dependence of the correlation rate $\tau_{\mathrm{c}}{ }^{-1}$ does not follow a simple Arrhenius behaviour with a single activation energy. In the high temperature limit the activation energy corresponds to the barrier height $V_{3}$ minus the energy of the lowest torsional level, $E_{0}$, whereas, at low temperature, the apparent activation energy 

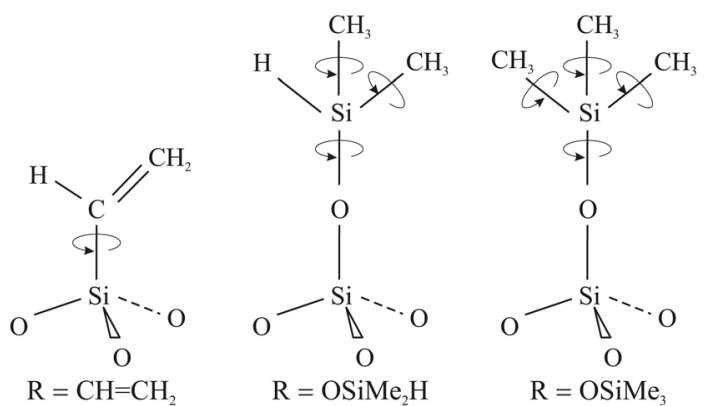

Fig. 7 Schematic representation of the $\mathrm{RSiO}_{3 / 2}$ units depicting the available rotation modes for each one of the three POSS derivatives.

is smaller and equals the energy difference between the first excited and ground torsional states, $E_{01}=E_{1}-E_{0}{ }^{24}$ This biexponential character of the correlation rate $\tau_{\mathrm{c}}{ }^{-1}$ has been experimentally observed for methyl group tunneling by NMR and inelastic neutron scattering (INS) techniques, ${ }^{25,26}$ and is in line with the two different activation energies obtained for $\mathrm{H} @\left(\mathrm{CH}_{2} \mathrm{CH}\right)_{8} \mathrm{Si}_{8} \mathrm{O}_{12}$, namely $E_{\mathrm{a}}=0.31 \mathrm{kcal} \mathrm{mol}^{-1}$ and $E_{\mathrm{a}}=$ $0.11 \mathrm{kcal} \mathrm{mol}^{-1}$ at high and low temperature, respectively.

Apart from the significant discrepancy between the activation energies of $\mathrm{H} @\left(\mathrm{CH}_{2} \mathrm{CH}\right)_{8} \mathrm{Si}_{8} \mathrm{O}_{12}$ and $\mathrm{Q}_{8} \mathrm{M}_{8}$ derivatives $\left(\mathrm{H} @ \mathrm{Q}_{8} \mathrm{M}_{8}^{\mathrm{H}}\right.$ and $\mathrm{H} @ \mathrm{Q}_{8} \mathrm{M}_{8}$ ) in the fast motional limit, a noteworthy difference concerns the minimum observed $T_{\mathrm{M}}$ value occurring at coalescence, i.e. when $R=\Delta$. In this limit, the slow motional formula $T_{\mathrm{M}}=\tau_{\mathrm{c}}$ gives $\Delta \approx T_{\mathrm{M}}{ }^{-1}$ from which the values $\Delta \approx 200 \mathrm{kHz}$ and $\Delta \approx 1 \mathrm{MHz}$ can be inferred for $\mathrm{H} @\left(\mathrm{CH}_{2} \mathrm{CH}\right)_{8}$ $\mathrm{Si}_{8} \mathrm{O}_{12}$ and $\mathrm{H} @ \mathrm{Q}_{8} \mathrm{M}_{8}$, respectively. The much smaller anisotropic averaged splitting $\Delta$ found for $\mathrm{H} @\left(\mathrm{CH}_{2} \mathrm{CH}\right)_{8} \mathrm{Si}_{8} \mathrm{O}_{12}$ reflects the reduced rotational modes of the organic substituent $\mathrm{R}$, namely the reorientation of the vinyl groups around the $\mathrm{Si}-\mathrm{C}$ bonds, in contrast to the more flexible rotation of $\mathrm{R}$ in the methyl-containing species, as illustrated in Fig. 7. Clearly, this result shows that the rotational dynamics of the peripheral organic groups of the cage play a key role in the determination of the electron spin coherence properties of the encapsulated hydrogen atom. Proper design of POSS cages by taking into account this new aspect would help to increase the $T_{\mathrm{M}}$ of atomic hydrogen to such a level that H@POSS could rival endohedral fullerenes.

\section{Conclusions}

The electron spin relaxation properties of atomic hydrogen encapsulated in $\left(\mathrm{CH}_{2} \mathrm{CH}\right)_{8} \mathrm{Si}_{8} \mathrm{O}_{12}$ cages were studied in detail with pulse EPR methods. The comparison with derivatives bearing different organic substituents $\mathrm{R}$, namely $\mathrm{Q}_{8} \mathrm{M}_{8}$ and $\mathrm{Q}_{8} \mathrm{M}_{8}^{\mathrm{H}}$, showed similar $T_{1}$ values for all species implying that spin-lattice relaxation is mainly determined by the dynamics of the core cage $\mathrm{Si}_{8} \mathrm{O}_{12}$. In contrast to this, the temperature dependence of $T_{\mathrm{M}}$ revealed that electron spin coherence is very sensitive to the type of peripheral organic groups. These results showed for the first time that the rotational dynamics of $\mathrm{R}$ have a major impact on both the temperature dependence of $T_{\mathrm{M}}$ and the minimum $T_{\mathrm{M}}$ value occurring at coalescence, $R=\Delta$. As nuclear spin diffusion is the leading dephasing mechanism in proton-containing ligands, deuterium isotopic substitution seems to be an obvious approach to increase $T_{\mathrm{M}}$. Our present work identified the rotational degrees of freedom of the cage substituents as a new key factor that affects electron spin coherence times, and therefore, should also be taken into account in the design of $\mathrm{H} @$ POSS species for quantum computing applications. We anticipate that this combination could result in molecular spin systems with unprecedented large $T_{\mathrm{M}}$ values and also shed light into other decoherence mechanisms that are typically masked by nuclear spin diffusion.

\section{Conflicts of interest}

There are no conflicts to declare.

\section{Acknowledgements}

We acknowledge support of this work by the project MIS 5002567, implemented under the "Action for the Strategic Development on the Research and Technological Sector", funded by the Operational Programme "Competitiveness, Entrepreneurship and Innovation" (NSRF 2014-2020) and co-financed by Greece and the European Union (European Regional Development Fund).

\section{Notes and references}

1 R. Sasamori, Y. Okaue, T. Isobe and Y. Matsuda, Science, 1994, 265, 1691-1693.

2 M. Paech and R. Stoesser, J. Phys. Chem. A, 1997, 101, 8360-8365.

3 H. Dilger, E. Roduner, R. Scheuermann, J. Major, M. Schefzik, R. Stoesser, M. Paech and D. G. Fleming, Physica B, 2000, 289290, 482-486.

4 B. Gross, H. Dilger, R. Scheuermann, M. Paech and E. Roduner, J. Phys. Chem. A, 2001, 105, 10012-10017.

5 M. Kaupp, J. Asher, A. Arbuznikov and A. Patrakov, Phys. Chem. Chem. Phys., 2002, 4, 5458-5466.

6 W. Harneit, in Spin Quantum Computing with Endohedral Fullerenes, ed. A. A. Popov, Springer International Publishing, Cham, 2017, pp. 297-324.

7 N. Weiden, M. Paech and K. Dinse, Appl. Magn. Reson., 2001, 21, 507-516.

8 R. S. Schoenfeld, W. Harneit and M. Paech, Phys. Status Solidi B, 2006, 243, 3008-3012.

9 G. Mitrikas, Phys. Chem. Chem. Phys., 2012, 14, 3782-3790. 10 L. D. Kispert, M. K. Bowman, J. R. Norris and M. S. Brown, J. Chem. Phys., 1982, 76, 26-30.

11 G. Mitrikas, E. K. Efthimiadou and G. Kordas, Phys. Chem. Chem. Phys., 2014, 16, 2378-2383.

12 N. Jalarvo, O. Gourdon, G. Ehlers, M. Tyagi, S. K. Kumar, K. D. Dobbs, R. J. Smalley, W. E. Guise, A. Ramirez-Cuesta, C. Wildgruber and M. K. Crawford, J. Phys. Chem. C, 2014, 118, 5579-5592. 
13 P. G. Harrison and C. Hall, Main Group Met. Chem., 1997, 20, 515-529.

14 C. Bonhomme, P. Tolédano, J. Maquet, J. Livage and L. Bonhomme-Coury, J. Chem. Soc., Dalton Trans., 1997, 1617-1626.

15 S. Stoll and A. Schweiger, J. Magn. Reson., 2006, 178, 42-55. 16 S. S. Eaton and G. R. Eaton, eMagRes, 2016, 5, 1543-1556.

17 S. S. Eaton and G. R. Eaton, Biological Magnetic Resonance, in Distance Measurements in Biological Systems by EPR, ed. L. J. Berliner, G. R. Eaton and S. S. Eaton, Springer US, 2000, vol. 19, pp. 29-154.

18 D. W. Feldman, J. G. Castle and J. Murphy, Phys. Rev., 1965, 138, A1208-A1216.

19 I. M. Brown, in Time Domain Electron Spin Resonance, ed. L. Kevan and R. N. Schwartz, Wiley, New York, 1979, ch. 6, p. 201.
20 G. M. Zhidomirov and K. M. Salikhov, Sov. Phys. JETP-USSR, 1969, 29, 1037-1040.

21 J. B. Lambert, R. J. Nienhuis and J. W. Keepers, Angew. Chem., Int. Ed. Engl., 1981, 20, 487-500.

22 P. A. Beckmann, C. W. Mallory, F. B. Mallory, A. L. Rheingold and X. Wang, ChemPhysChem, 2015, 16, 1509-1519.

23 A. Schweiger and G. Jeschke, Principles of Pulse Electron Paramagnetic Resonance, Oxford Univ. Press, New York, 2001.

24 A. Horsewill, Prog. Nucl. Magn. Reson. Spectrosc., 1999, 35, 359-389.

25 W. Müller-Warmuth, R. Schüler, M. Prager and A. Kollmar, J. Chem. Phys., 1978, 69, 2382-2392.

26 M. V. Cleemput, A. Buekenhoudt, L. V. Gerven and A. J. Horsewill, J. Chem. Phys., 1995, 103, 2787-2794. 